\title{
Prediction of evapotranspiration using Fuzzy logic
}

\author{
PRANITA N. BALVE and JAYANTILAL N. PATEL \\ Civil Engineering Department, Sardar Vallabhbhai National Institute of Technology, Surat \\ Email: balvepranita21@rediffmail.com
}

\begin{abstract}
In this paper, evapotranspiration prediction is done using Fuzzy Inference System (FIS) of Fuzzy Logic.For the prediction of evapotranspiration, mean temperature, relative humidity, wind speed and net radiation is taken as inputs to the fuzzy inference system. To check the efficiency of the FIS model, the results were compared with the FAO-56 Penman Monteith (FPM-56) method. FIS model has given the coefficient of determination $\left(R^{2}\right)$ 0.979. Results indicated that, FIS model has better efficiency for prediction of evapotranspiration
\end{abstract}

Key Words : Evapotranspiration, Penman-Monteith method, Fuzzy Inference System, Fuzzy If- Then Rules.

Evapotranspiration (ET) is important process of hydrological cycle. It is combination of two processes like evaporation and transpiration. ET plays major role in the planning and management of waer resources system, irrigation system, design and drainage studies, etc. India is agriculture country and accurate estimation of ET is necessary because overestimation and under estimation of ET cause wastage of valuable source of water, crop yield respectively.

On field, the evapotranspiration can be measured by using lysimeter and field plots. But it does not give exact value of the ET. As the field condition and soil strata are different at different places. Such field test takes more time and results are not accurate. These results depend upon field conditions so the result varies over the area. These difficulties in obtaining the reliable results of evapotranspiration have given rise to a number of methods of calculating and predicting the reference evapotranspiration(ETo) from the avaialable meteorological data.

The evapotranspiration either ETo or potential evapotranspiration (PET) can be calculated by various approaches like, radiation based, temperature based, mass transfer based or pan evaporation based equations or the fusion of the available meteorological data. PenmanMonteith (FPM-56) method is standard method of determining the ETo and results of it shows better performance when compared with other existing methods. The FPM-56 equation requires the detail meteorological data for evaluation of ETo because it provides consistent ETo values in various region and climates (Allen, et at. 1998, Tabari and Hosseinzadeh, 2011).
In recent years, fuzzy logic is applied to the many applications as it is an alternative and effective tool for studying complex phenomenon. FIS have been successfully used in reservoir management (Panigrahi and Mujumdar, 2000), rainfall-runoff problems (Nayak et al., 2005; Yu and Chen, 2005) and in parameters of groundwater flow. Conventional model require more parameters to estimate the ETo for same all regions and climate conditions (Tzimopoulos et al., 2008). The ETo is estimated (Patel and Balve, 2016) using FIS considering parameters of ETo as inputs. The different approaches like temperature based, radiation based, pan evaporation and mass transfer based were used to estimate the evapotranspiration (Balve and Patel, 2016) and comparision is done with FPM-56 and best suited methods of estimating evapotranspiration is found out. Kisi and Ozturk (2007) used the neurofuzzy and ANN model to estimate the FAO-56 PM ET0 using the observed climatic variables. Also investigated ability of fuzzy genetic (FG) approach in modelling of reference evapotranspiration and it is observed that FG approach is superior in modelling daily ETo than the other models.

\section{MATERIALS AND METHODS}

In this study the evapotranspiration is predicted for future period on daily basis scale from the available meteorological data using fuzzy inference system. Fuzzy logic base modelling of determination of evapotranspiration is a simple approach, which operates on an 'if-then' principle. The results obtained from fuzzy inference system were compared with evapotranspiration calculated using Penman Monteith FAO-56 method. The root-mean-square errors (RMSE), sum of square error (SSE), mean-absolute errors (MAE), and coefficient of determination statistics are used 
as comparing criteria for the evaluation of the models performances.

\section{Study area and data}

The data of Takali meteorological station in Nashik district of Maharashtra state, India is considered in this study. The station is located on river Godavari at latitude of $19^{0} 58^{\prime} 60^{\prime \prime} \mathrm{N}$ and a longitude of $73^{\circ} 47^{\prime} 60^{\prime \prime} \mathrm{E}$. The climatic parameters including maximum and minimum air temperature, relative humidity, evaporation, sunshine duration, rainfall, wind speed were taken from Hydrological Data User Group (HDUG), MERI of daily data for the period of 2006 to 2010.

\section{Penman-Monteith method}

In 1990, the FAO Penman-Monteith method was advised as the global standard method for the computation and definition of the reference evapotranspiration (Allen $e t$ at., 1998). As it requires meteorological data like radiation, mean air temperature, relative humidity and mean wind speed data for daily, weekly, ten day or monthly calculation of reference ETo and it is given by the following relation as,

ETo $=\frac{0.408 \Delta\left(\mathrm{R}_{\mathrm{n}}-\mathrm{G}\right)+\gamma\left(\frac{900}{\mathrm{~T}_{\mathrm{g}}+27 \mathrm{~s}}\right) \mathrm{u}_{2}\left(\mathrm{e}_{\mathrm{g}}-\mathrm{e}_{\mathrm{g}}\right)}{\Delta+\gamma\left(1+0.34 \mathrm{u}_{2}\right)}$

Where, ETo is reference evapotranspiration $\left[\mathrm{mm} \mathrm{day}^{-1}\right], \mathrm{Rn}$ is net radiation at the crop surface $\left[\mathrm{MJ} \mathrm{m}^{-2}\right.$ day $\left.^{-1}\right], \mathrm{G}$ is soil heat flux density [ $\left.\mathrm{MJ} \mathrm{m}^{-2} \mathrm{day}^{-1}\right]$, Ta is daily air temperature at $2 \mathrm{~m}$ height $\left[{ }^{\circ} \mathrm{C}\right], \mathrm{u}_{2}$ is wind speed at $2 \mathrm{~m}$ height $\left[\mathrm{m} \mathrm{s}^{-1}\right]$, es is saturation vapour pressure $[\mathrm{kPa}]$, ea is actual vapour pressure $[\mathrm{kPa}]$,es-ea is saturation vapour pressure deficit $[\mathrm{kPa}], \Delta$ is slope of vapour pressure curve $\left[\mathrm{kPa}^{\circ} \mathrm{C}^{-1}\right], ?$ is psychometric constant $\left[\mathrm{kPa}^{\circ} \mathrm{C}^{-1}\right]$.

The detailed calculation of the each and every parameter of ETo is given in (Allen, et al., 1998). This method is considered as standard method for comparison of ETo with different approaches.

\section{Fuzzy inference system}

Fuzzy inference process involves membership functions, logical operations, and if-then rules. A fuzzy inference system defines with the conditions, from the given condition conclusion is drawn, and nature of the conclusion is in the form of fuzzy. 'If' is a vector of fuzzy explanatory variables or premises or antecedent, whichdescribes the condition. In 'If' part of the statement inputs are connected by AND or OR connectives. The 'then' is a fuzzy consequence or conclusion such as evapotranspiration of the study area.

In modelling of estimation of evapotranspiration with fuzzy logic, the following steps are conducted.

\section{Fuzzification of inputs}

The first step is to take the crisp inputs mean temperature, relative humidity, wind speed, net radiation and output as evapotranspiration and determine the degree to which these inputs and output belong to each of the appropriate fuzzy sets. The input is always a crisp numerical value limited to the universe ofdiscourse of the input variable and the result of first step is a fuzzy degree ofmembership with proper shape of membership function.

\section{Formulation of fuzzy rule set and application of operators}

The second step is to take the fuzzified inputs and apply them to the antecedents of the fuzzy rules. If a given fuzzy rule has multiple antecedents then for maximization problem OR and for minimization problem AND connections are used to connects the multiply antecedents.

\section{Aggregation of the rule outputs}

Aggregation is the process of unification of the outputs of all the rules. The input for the implication method is single number resulting from premise, and the result of implication is fuzzy set. Implication occurs for each rule by the AND method which truncates the output fuzzy set.

\section{Defuzzification of the rules}

The last step in fuzzy inference process is defuzzification. Fuzziness helps us to evaluate the rules, but the final output of a fuzzy system has to be a crisp number. The input for the defuzzification process is the aggregate output fuzzy set and output is a single number. In this study, the centroid method of defuzzification is used as it directly computes the real value output as normalised combination of membership values. It is given by the expression as,

$$
G=\frac{\sum_{i=1}^{n} y_{i} \mu_{s}\left(y_{i}\right)}{\sum_{i=1}^{n} \mu_{s}\left(y_{i}\right)}
$$

Where, $\mathrm{G}$ is centroid of the truncated fuzzy output set. The centroid method of defuzzification yields a unique crisp number in the output distribution.

\section{Evaluation criteria}

In this paper, root-mean-square error (RMSE), sum of square error (SSE), mean-absolute errors (MAE), and coefficient of determination (R2) are used for evaluation of 


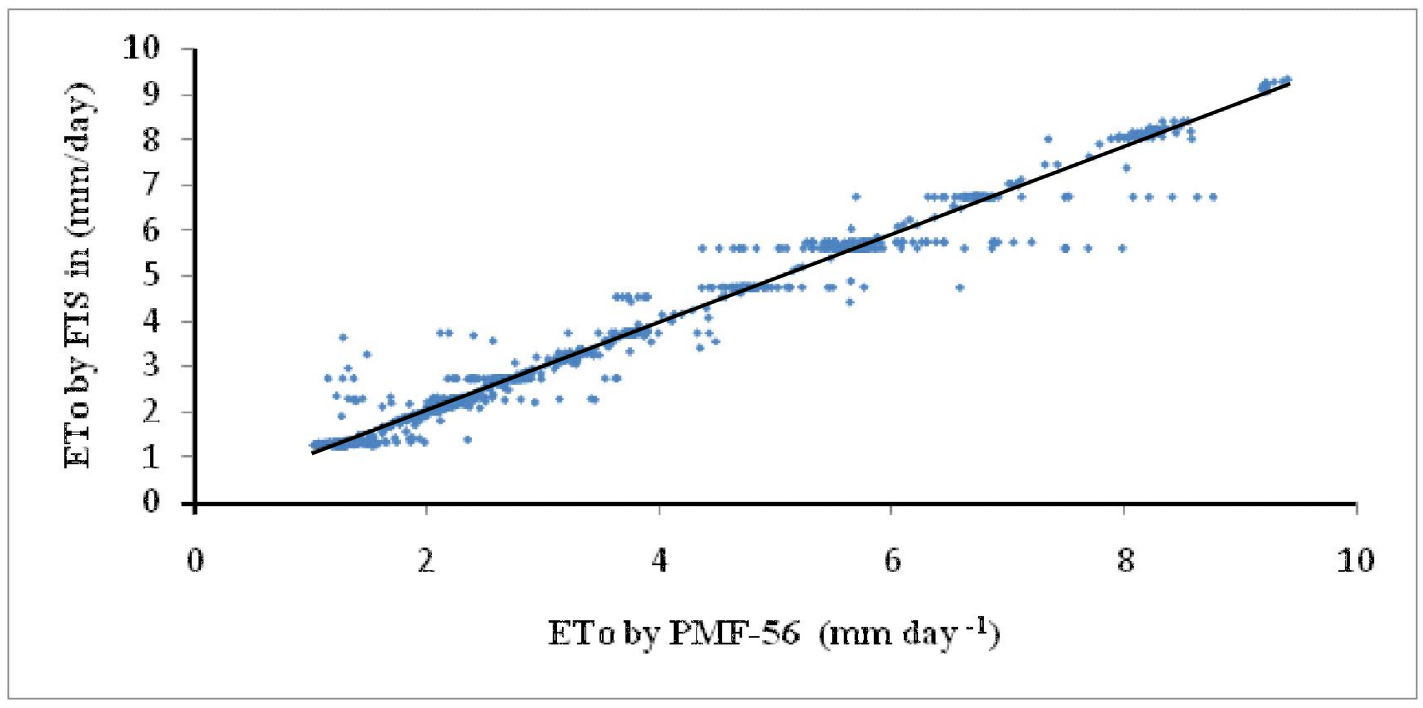

Fig.1 : Comparison of ETo obtained by FIS with that of FDM-56 method

Table 1: $\mathrm{R}^{2}$, RMSE, SSE, MAE of the FPM-56 and FIS for year between 2006-2010

\begin{tabular}{lrrrr}
\hline Year & $\mathrm{R}^{2}$ & RMSE & SSE & MAE \\
\hline 2006 & 0.9737 & 0.3406 & 38.98 & 0.1595 \\
2007 & 0.9715 & 0.3124 & 33.87 & 0.1350 \\
2008 & 0.9943 & 0.1652 & 8.86 & 0.0759 \\
2009 & 0.9821 & 0.2373 & 18.29 & 0.1124 \\
2010 & 0.9750 & 0.3173 & 24.57 & 0.1411 \\
over all & 0.9794 & 0.2862 & 129.79 & 0.1267 \\
\hline
\end{tabular}

the different approaches of the ETo equation and are defined as,

$$
\begin{aligned}
& R M S E=\sqrt{\frac{\left.\sum_{i=1}^{n}\left(P_{i}-\bar{O}_{i}\right)\right)^{2}}{n}} \\
& R^{2}=\frac{\left\{\sum_{i=1}^{n}\left(P_{i}-\bar{P}\right)\left(O_{i}-\bar{O}\right)\right\}^{2}}{\sum_{i=1}^{n}\left(P_{i}-\bar{P}\right)^{2} \sum_{i=1}^{n}\left(O_{i}-\bar{O}\right)^{2}} \\
& S S E=\sum_{i=1}^{n}\left(O_{i}-P_{i}\right)^{2} \\
& M A E=\frac{\sum_{i=1}^{n}\left|O_{i}-P_{i}\right|}{n}
\end{aligned}
$$

Where, Pi and Oi are the predicted and observed values, respectively; $\mathrm{P}^{-}$and $\mathrm{O}^{-}$are average of $\mathrm{Pi}$ and $\mathrm{Oi}$ and $\mathrm{n}$ is the total number of data.

\section{RESULTS AND DISCUSSIONS}

The methodology discussed in the previous section is used for estimation of evapotranspiration on daily basis and implemented to the Takali meteorological station of Nashik district, Maharashtra state, India.The evapotranspiration values of the study area are determined by using FAO-56 Penman-Monteith method for daily data. The fuzzy logic tool box available with the MATLAB package is used for developing the model. The inputs to the fuzzy system are inputs mean temperature, relative humidity, wind speed and net radiation. The output is the daily evapotranspiration.

The implication method 'Min' produces a clipped output fuzzy set and defuzzification method 'Centroid' is as discussed earlier is used for 'Defuzzification of the Rules'. As the number of membership functions for input/output increases, the error decreases. But as the number of membership functions increases the number of rules in the rule base also increases. Thus there is, a trade-off between the number ofmembership functions and the number of rules.

To check the fitness of the obtained data with calculated, $\mathrm{R}^{2}$, RMSE, SSE and MAE values are also determined yearly and also for the period from 2006 to 2010 and are shown in Table 1.

In year 2006, except March and April in remaining months all the ETo shows under prediction. Whereas in 2007 , sometimes shows exact and at some periods shows under predictions. The predicted and calculated value of ETo in year 2008 shows exact prediction in all the time periods. The predicted value indicates that, can be used for the future prediction if sufficient meteorological data series is available. The SSE is used to measure the variation within a cluster. If all the values are within a cluster are the identical 
case for SSE and in this case, SSE would be equal to zero. The MAE value is used to measure how close predictions are to the eventual outcomes.

The prediction for year 2009 and 2010 shows that, there is very less difference between predicted and calculated values of ETo. To check the fitness of the obtained results, predicted values of ETo by FIS were plotted against the calculate values of ETo by FPM-56 (Fig.1).

The $\mathrm{R}^{2}$ values of all the year between 2006 to 2010 shows good values and it is more than 0.96 . Also, the $\mathrm{R}^{2}$ value for combine values between 2006 to 2010 shows the value of 0.9794 and RMSE value obtained to be 0.2862 . It indicates that, predicted and calculated values show good measures of accuracy. The fuzzy inference system can be used in future for prediction.

\section{CONCLUSION}

Fuzzy inference system has given results and performance at par with Penman Monteith method and shows FIS can be used for the further prediction of ETo. It is concluded that the fuzzy inference system had capability to predict the evapotranspiration if the sufficient daily data is available for the prediction.

\section{REFERENCES}

Allen, R. G., Pereira, L. S., Raes, D., and Smith, M. (1998). Crop evapotranspiration-Guidelines for computing crop water requirements-FAO Irri. \& drain paper 56. FAO, Rome, 300(9), D05109.
Balve, P. and Patel, J. (2016). Comparison of different approaches of computation of evapotranspiration. Int. J. Earth Sci.\&Engg., 9(1):18-29.

Kisi, O. and Ozturk, O. (2007). Adaptive neuro-fuzzy computing technique for evapotranspiration estimation. J. Irrig. Drain. Eng., 133(4):368-379.

Nayak, P. Sudheer, K. and Ramasastri, K. (2005).Fuzzy computing based rainfall-runoffmodel for real time flood forecasting. J. Hydrol. Proces., 19:955-968.

Panigrahi, D. and Mujumdar, P., (2000). Reservoir operation modelling with fuzzylogic. J. Water Resour. Res., 14:89109.

Patel, J. N. and Balve, P. N. (2016). "Evapotranspiration estimation with fuzzylogic". Proce. of 40th The IRES Int. Conference, Zurich, Switzerland, 10th June 2016, pp 20 23.

Tabari, H. and Hosseinzadeh, T. P. (2011). Local calibration of the Hargreaves and Priestley-Taylor equations for estimating reference evapotranspiration in arid and cold climates of Iran based on the Penman-Monteith model. J. Hydro. Engg., 16(10):837-845.

Tzimopoulos, C., Mpallas, L. and Papaevangelou, G. (2008). Estimation of evapotranspiration using fuzzy systems and comparison with the Blaney-Criddle method.J. Env. Sci.\& Tech., 1(4):181-186.

Yu Pao Shan and Shien Tsung Chen (2005). Updating real-time flood forecasting using a fuzzy rule-based model. $J$. Hydrol. Sci., 50:265-278. 